\title{
Aprobación de Planes Generales de Ordenación Urbana en el Derecho Autonómico Valenciano
}

\author{
Ignacio Sevilla Merino \\ Profesor Titular de Derecho Administrativo \\ Universitat de Valéncia
}

Sumario: I. OBSERVACIONES PROCEDIMENTALES Y URBANISTICAS SOBRE EL TEMA. II. ELABORACIÓN DEL PLANEAMIENTO MUNICIPAL. 1. El concierto entre el Municipio y la Comunidad Autónoma. 2. Información a otras Administraciones. 3. Publicidad en la elaboración. 4. Subrogación de la Comunidad Autónoma. III. TRAMITACIÓN. 1. Ausencia de aprobación inicial. 2. Información pública. 3. Aprobación provisional. A. Contenido. a. Aprobación provisional y participación ciudadana. b. Aprobación provisional y conflictos interadministrativos. a'. Planteamiento del conflicto. b'. Resolución del conflicto. c'. Contenido de la resolución del conflicto. B. Aprobación provisional y modificaciones sustanciales. IV. APROBACIÓN DEFNITIVA. 1. Regulación legal. 2. Periodo consultivo, en particular, los informes oportunos y el ofrecimiento de alternativas técnicas. 3. Tipología. A. Aprobación definitiva expresa. B. Suspensión de la aprobación. C. Aprobación parcial. D. Aprobación condicionada. E. Aprobación por silencio administrativo. F. Denegación de la aprobación.

El legislador valenciano aprobó el 15 de noviembre de 1994 la Ley Reguladora de la Actividad Urbanística ', ambicioso y extenso texto, cuyo confeso propósito «excede la mera adaptación de la ley estatal a las peculiaridades autonómicas» y, aunque dice respetar la Ley del Suelo de 1992, pretende «formular una alternativa al sistema vigente en la dimensión propiamente urbanística... Se pretende sustituir el antiguo modelo - respetando las normas de legislación básica o plena estatal-por una nueva orientacións ${ }^{2}$.

Con tales presupuestos no es de extrañar que el legislador haya abordado las cuestiones relativas al contenido y funcionalidad de los planes urbanísticos, locales y supramunicipales, pero también el procedimiento de aprobación de los mismos, cuestión en la que va a centrarse este trabajo, para lo cual es preci-

\footnotetext{
1 En adelante, LRAU.

2 Cfr. Exposición de Motivos LRAU.
} 
so establecer a previamente el punto de partida, la situación de la cuestión de la que partió el legislador autonómico valenciano.

\section{OBSERVACIONES PROCEDIMENTALES Y URBANISTICAS SOBRE EL TEMA}

Esto exige distinguir dos planos diferentes en esta cuestión.

Si se considera el procedimiento en abstracto, se tiende a considerar que todo lo actuado previamente a la aprobación llamada definitiva (en realidad, la única aprobación), son trámites equivalentes a los de iniciación y propuesta de resolución.

Por el contrario, si en lugar de esa perspectiva se adopta la puramente urbanística, las consecuencias son notablemente distintas, puesto que entonces se aprecia que es el Ayuntamiento quien fija el momento en que va a intervenir, cómo va a hacerlo, qué instrumento va a emplear y, en definitiva, elige el modelo urbanístico del municipio.

Desde una consideración simplemente procedimental, lo primero que hay que observar es que el legislador autonómico valenciano no parece haber tenido en cuenta la Ley de Régimen Jurídico de las Administraciones Públicas y del Procedimiento Administrativo Común ${ }^{3}$.

La Administración Valenciana no había cumplido con lo dispuesto en la D. Adicional 3. ${ }^{a}$ de la Ley 30/92, sobre adecuación de procedimientos, como tampoco lo ha hecho la Administración del Estado. Ahora bien, la situación es distinta, la primera de ellas fijó, mediante Decreto del Consell 166/1994, los términos de aplicación de la Ley $30 / 92$ a distintos procedimientos y también los urbanísticos, donde sólo se hace mención de los de la Ley 4/92, de Suelo no urbanizable.

No se trata de valorar, sino sólo de relacionar la actuación de distintas Administraciones públicas, con lo cual la obligación disminuye en intensidad y también cabe pensar que la regulación que contiene la Ley valenciana supone la manifestación expresa de su autor sobre el particular ${ }^{4}$.

3 En adelante, LPC.

4 En línea con otras normas o proyectos que vuelven a antiguas reglas procedimentales como es el caso del proyecto de Ley reguladora de la Jurisdicción Contencioso-Administrativa. 
APROBACIÓN DE PLANES GENERALES DE ORDENACIÓN URBANA...

Se trata, por consiguiente, de considerar que, fundamentalmente, por seguridad jurídica, deberian homogeneizarse los procedimientos.

Lo anterior al margen, varias de las situaciones reguladas en esta Ley resultan, procedimentalmente, bastante desafortunadas; entre ellas, no son las menos llamativas las provocadas por ciertas expresiones empleadas por el legislador valenciano.

Así, por lo que atañe al objeto de este trabajo, suscita perplejidad la utilización de conceptos jurídicos indeterminados cuya interpretación dependerá de la Comunidad Autónoma y que pueden dar paso a la sustitución de la competencia municipal por la autonómica, en la elaboración del planeamiento ${ }^{5}$. De todo ello se tratará más adelante, no obstante, cabe dejar sentado ya ahora que son cuestiones que denotan una cierta inseguridad, al margen de que en otros casos se trate de expresiones a las que ya ha dado un significado concreto la LPC.

Con independencia de ello, no se puede perder de vista la dimensión urbanística de las decisiones municipales, máxime ante el estado jurisprudencial de la cuestión, en que estas decisiones determinan - al menos, parcialmente- el contenido de la que al final haya de adoptar la Comunidad Autónoma.

La vigente LS no introdujo grandes novedades en el apartado dedicado a la aprobación de los planes urbanísticos municipales, respecto a la legislación anterior. Las razones que justifican tal decisión las he estudiado y expuesto con anterioridad $^{6}$.

La LRAU ha mantenido este esquema. No obstante, desde el punto de vista de la filosofia de la norma, la supremacía que en el Derecho estatal disfruta la ordenación respecto de la gestión urbanística queda muy desdibujada?

Parece evidente que el legislador valenciano ha querido poner fundamentalmente el acento en la gestión, lo que se adivina casi desde la propia denominación de la Ley, ahora bien, no es menos cierto que para ello no era preciso alterar tan sensiblemente la funcionalidad de la ordenación, respecto del punto

5 Se hace referencia a la acomodación del plan a «circunstancias que justificadamente lo aconsejen", art. 35,1; o a la elaboración autonómica directa si la «situación urbanística (del municipio) lo requiere», art. 36; no son menores las dificultades que plantea el uso de la expresión "preceptivas negociaciones)" con los municipios colindantes, los «acuerdos» con entidades representativas de colectivos ciudadanos afectados, el "concierto" con la Consellería competente, los uacuerdos interadministrativos» llamados a sustituir a los informes o el «desacuerdo» entre municipios colindantes.

6 Vid. I. SeVLla Merino, La responsabilidad patrimonial de la Administración por la aprobación de planes urbanisticos municipales, FVM y P-Civitas, Valencia, 1994, págs. 84 y ss.

7 Cfr., por ejemplo, art. 54, 1, B LRAU. 
de partida. No es ésta una afirmación que pueda justificarse apresurada o brevemente y por eso cabe reducirla a la categoría de simple impresión de quien se enfrenta al texto con la intención de abordar otras cuestiones distintas que el mismo plantea, pero que habrá de ser considerada con mayor detenimiento.

Así pues, queda ahora la cuestión en la manifestación de que la LRAU distingue entre ordenación y gestión urbanística ${ }^{8} \mathrm{y}$, dentro de la ordenación, distingue entre elaboración o formulación del proyecto y tramitación propiamente dicha. El primero de dichos aspectos queda sin embargo absorbido por el segundo.

A pesar de ello, la elaboración del proyecto para su ulterior trámite es un aspecto trascendental de lo que llegará a ser el Plan, en la medida que es el germen del mismo.

La LRAU reconoce con claridad la competencia municipal, aunque -como consecuencia del desvaimiento aludido - parece confundir la elaboración con la creación del primer planeamiento. Sólo así se explica que el art. 35 hable de "elaborar, modificar o revisar», cuando lo lógico es que se hiciese referencia a la elaboración de los planes, de sus modificaciones y revisiones.

\section{ELABORACIÓN DEL PLANEAMIENTO MUNICIPAL}

\section{El concierto entre el municipio y la Comunidad Autónoma}

La LRAU contiene innovaciones interesantes. Entre ellas, el hincapié que hace en la colaboración institucional que debe presidir la elaboración municipal del planeamiento, hasta el punto de imponer una cierta supervisión autonómica sobre la misma, que, no obstante, puede ser entendida como un esfuerzo en aras de la eficacia.

La Ley facilita a la Comunidad Autónoma el ejercicio de facultades de expectación o vigilancia sobre la actuación municipal al declarar preceptivo el «concierto» con la Administración autonómica en la definición del modelo territorial municipal para que resulte acorde con su contexto supramunicipal, cuando el proyecto de plan esté siendo redactado (art. 38,1 LRAU).

Desde luego, esta obligación ha de ser considerada favorablemente, en la medida que simplifique la ardua labor de redacción del planeamiento general y se

8 E. Garcia de Enterria y L. Parejo Alfonso, Lecciones de Derecho Urbanistico, Civitas, Madrid 1981. 
APROBACIÓN DE PLANES GENERALES DE ORDENACIÓN URBANA..

integra fácilmente en los deberes de mutua información y colaboración entre las Administraciones Públicas ${ }^{9}$, en particular, cuando ambas son competentes.

Resulta llamativo, sin embargo, el empleo de la expresión concierto, para definir las relaciones entre Ayuntamiento y Consellería competente en Urbanismo.

Es cierto que el legislador urbanístico nos ha acostumbrado hasta ahora a un marco acentuadamente tradicional de relaciones de la Administración urbanística con los ciudadanos, así como de aquella con las restantes Administraciones. Buena muestra de ello son los arts. 244 y 303 de la LS; ahora bien, la LRAU ha denominado concierto a la relación que ha de entablarse entre el Ayuntamiento y la Comunidad Autónoma y con ello utiliza una expresión hasta ahora reservada por el Ordenamiento urbanístico para referirse a los acuerdos a que podían llegar la Administración y los ciudadanos con el fin de resolver o, al menos, simplificar las dificultades inherentes a la gestión urbanística, a partir de la llamada acción concertada, surgida ya hace veinte años en el seno de los planes de desarrollo económico y social ${ }^{10}$.

A mayor abundamiento, el carácter preceptivo de estos conciertos, no sólo hace que el término rompa con la idea que tanto vulgar como jurídicamente puede atribuírsele, sino - que es lo que aquí interesa- supone una clara invasión de lo que hasta el presente era una competencia atribuida al municipio. Recuerda a la autorización previa que quienes traten de elaborar planes de iniciativa particular deben solicitar del Ayuntamiento, al amparo del art. 104,3 de la LS — que no ha sido desplazado ${ }^{11}$-, si pretenden que la Administración les proporcione luego los elementos informativos y demás facilidades que precisasen; aun así, dicha autorización queda formalmente configurada como de solicitud voluntaria, caso distinto a éste.

Es verdad que el objeto de los conciertos es solamente la adecuada ubicación del proyecto de plan general en el marco físico y jurídico en que ha de situarse y ello ha de entenderse como algo enteramente razonable y legítimo, pero también lo es que el primero de estos objetivos puede lograrse mediante las consultas con los municipios limítrofes (art. 38,1, párf. $2^{\circ}$, LRAU) y que el segundo, la adecuación a los Planes de Acción Territorial ${ }^{12}$, es un problema de jerarquía del planeamiento, que parece innecesario tratar de resolver por este cauce.

\footnotetext{
9 Cfr.: arts. 10 y 55, LRL y 4 LPC.

10 Vid. E. Garcia de Enterría y T. R. Fernández Rodriguez, Curso de Derecho Administrativo I, 7. ${ }^{\circ}$ Ed. Civitas, Madrid, 1995, pág. 645 y ss.

11 Vid. D. F. I. LRAU.

12 En adelante, PAT, vid. art. 16 LRAU.
} 
En definitiva, de este modo queda liquidado el dominio que sobre la elaboración del planeamiento tenía hasta ahora atribuido el municipio (art. 109,1 LS), que implicaba, incluso en el caso de que éste encomendase la redacción material del plan a la Comunidad Autónoma, que ésta quedase vinculada por las instrucciones que al respecto le impartiese el municipio ${ }^{13}$.

\section{Información a otras Administraciones}

Naturalmente, no concluye en la Comunidad Autónoma el apartado de relaciones institucionales. El art. 38,1, LRAU, también declara preceptivas las «negociaciones》 y consultas con los municipios colindantes y las Administraciones Públicas cuyas competencias o bienes demaniales puedan verse afectados por el proyecto. De todo ello habrá de dejarse constancia en el expediente.

No resulta fácil desvelar cuál pueda ser el objeto de las negociaciones con los municipios colindantes, al margen de los planes de conjunto y otro tanto cabría decir de las restantes Administraciones Públicas, salvo lo ya establecido por normas sectoriales.

\section{Publicidad en la elaboración}

La Ley valenciana impone la obligación de que en esta fase de la elaboración del planeamiento el municipio consulte a las «entidades representativas de los colectivos ciudadanos particularmente afectados».

Esta obligación, que se alínea con la tendencia a potenciar y privilegiar las asociaciones privadas, no puede ser disociada de la supresión del carácter preceptivo que en el ámbito estatal tiene la publicación del Avance del proyecto de plan.

La LRAU suprime la obligación de publicar el llamado Avance de planeamiento, cuya formulación pública exige la normativa estatal en el art. 125 del $\mathrm{R}$ Planeamiento, que lo configura como un documento de trabajo, carente de eficacia vinculante, con efectos administrativos exclusivamente internos, preparatorios de la redacción del planeamiento ${ }^{14}$.

La eliminación de esta obligación incrementa el déficit de publicidad que en la LRAU experimentan los instrumentos de planeamiento, respecto al dispuesto por la legislación estatal. Ciertamente, la LRAU prevé los acuerdos

13 STS de 8 de junio de 1993; R 4521.

14 Art. 103,3, LS. Vid., no obstante, STS de 10 de marzo de 1987, R 3522. 
APROBACIÓN DE PLANES GENERALES DE ORDENACIÓN URBANA...

conentidades representativas de colectivos ciudadanos particularmente afectados, pero este trámite, a falta de mayores precisiones, recuerda bastante al art. 130,4, de la Ley de Procedimiento Administrativo y no resulta excesivamente necesaria la ilustración sobre la aplicación de este precepto ${ }^{15}$.

No debe ocultarse tampoco que, a cuenta de aligerar el tiempo de elaboración del plan y de evitarse el estudio de las sugerencias y alternativas que pudieran presentarse, las Corporaciones Locales verán cegada una fuente de información cuya utilidad ha sido recordada en ocasiones como asimilable a la garantía del acierto y oportunidad que orienta esta fase procedimental en la elaboración de disposiciones generales ${ }^{16}$.

\section{Subrogación de la Comunidad Autónoma}

Como excepciones a la elaboración municipal de su planeamiento general, la Ley establece dos supuestos distintos.

Habilita a la Comunidad Autónoma para requerir a los municipios que carezcan de planeamiento general o para que lo adapten a los PAT o a «circunstancias que justificadamente lo aconsejen» (art. 35,1).

La Administración autonómica podrá también elaborar directamente el Plan General de un municipio, cuando éste carezca del mismo o el que tenga haya sido anulado o suspendido «si su situación urbanística lo requiere» (art. 36).

Estos preceptos han desplazado al art. 109,5, de la LS, a la luz de la D.F. Primera de la LRAU, más bien cabría decir que han hecho efectiva la supletoriedad con que la D. Final de la LS concibió dicho precepto ${ }^{17}$.

Con independencia de que, en ambos casos, el Conseller competente deba de solicitar previamente el informe favorable, es decir, vinculante, del Consejo Superior de Urbanismo ${ }^{18}$, parece particularmente inquietante una configuración tan indeterminada, por no decir vaga, de la habilitación para efectuar requerimientos,

is Puede, no obstante, consultarse en J. J. Diez SÁNCHEZ, El procedimiento administrativo comín y la doctrina constitucional, Civitas, Madrid, 1992, págs. 124 y 183 y ss.

16

Vid. art. 129,1 LP Administrativo y STS de 10 de octubre de 1989, R 7351.

17 Cfr. L. Cosculluela Montaner, Manual de Derecho Administrativo, pág. 55, 6. Ed., Civitas, Madrid, 1995.

18 Figura en la D.A Primera de la Ley, como umáximo órgano asesor de las Administraciones Públicas con competencia urbanística de la Comunidad Valencianas, terminología confusa donde las haya, pero cuya composición, organización y funcionamiento, se determinarán reglamentariamente, lo que agrava la situación. 
dado que, en ambos casos, la intervención autonómica se produce a partir de unas premisas configuradas como auténticos conceptos jurídicos indeterminados, a interpretar, precisamente, por el sujeto llamado a intervenir.

Ambas disposiciones contienen, como causas que dan lugar a la elaboración autonómica directa del planeamiento general municipal ${ }^{19}$, supuestos que se solapan y que han sido objeto de una redacción deliberadamente ambigua.

En ambos casos se da la posibilidad de que la Comunidad Autónoma ejerza por subrogación competencias propias del Municipio, dado que en el art. 35,1, se hace referencia al art. 60 de la Ley reguladora de las bases del Régimen Local, en tanto que el art. 36 prevé este supuesto directamente. MARTINEZ GARCIA ${ }^{20}$ considera que ambas determinaciones tienen precedentes en la legislación estatal -respecto del art. $36 \mathrm{LRAU}$ cita el art. 130 de la LS - pero estima que el requerimiento debe ser interpretado en función de los imperativos de la coordinación y no como una facultad genérica de tutela. Esto es así en cuanto el art. 36 se refiere a circunstancias objetivas - carencia o anulación de planeamiento-y no lo es tanto en lo que atañe a la «situación urbanística», donde sólo una interpretación muy generosa de la competencia urbanística autonómica permitirá la pacífica aplicación de la habilitación legal. Esto se debe a que, en esencia, las subrogaciones no pueden presumirse, deben establecerse restrictivamente y para que se produzcan váli. damente es incontestable la necesidad del previo señalamiento de plazo ${ }^{21}$.

Estamos, en todo caso, ante una cierta manifestación de desconfianza en las administraciones locales, tradicional en la legislación urbanística, pero que,

19 Las Normas Subsidiarias de Planeamiento han desaparecido de la LRAU. No obstante, según los Apuntes sobre la ley reguladora de la actividad urbanistica, editados por la propia Conselleria de Obras Públicas, Urbanismo y Transportes, esta desaparición es puramente nominal, está previsto que reglamentariamente se adecue la exigencia documental a la complejidad de la situación urbanistica municipal (pág. 14) como efectivamente asi dispone el art. 27,1 C.), con carácter general. Ello al margen, el art. 36 limita ya no documental, sino sustantivamente el contenido de estos planes generales que se podrian denominar «de urgencia».

20 S. MARTíneZ Garcia, "Relaciones interinstitucionales en la Ley Reguladora de la Actividad Urbanistica. Las competencias urbanisticas de la Administración Autonómica y de los municipios», en Comentarios a la Ley Reguladora de la Actividad Urbanistica, Generalidad Valenciana, Valencia, pág. 231.

21 Lo cierto es que la percepción jurisprudencial de la subrogación implica considerar este instrumento de intervención en los asuntos municipales con carácter excepcional, como estableció la Sentencia del TS de 2 de octubre de 1979 (R 3289), pudiendo confrontarse, además, las de 13 de noviembre de 1989, R 8184 y STS de 21 de noviembre de 1990, — si bien las manifestaciones han apuntado normalmente al cumplimiento estricto de los requisitos formales que den paso a ella, es decir, la previa fijacion de un plazo- toda vez que el plazo supone un elemento esencial para la regularidad jurídica de la actuación autonómica- y su incumplimiento por la Administración local. 
como dice GonZÁlez Pérez ${ }^{2}$, se ha acentuado en las legislaciones autonómicas. Pese a que la LRAU razone lo contrario en su Exposición de Motivos, lo cierto es que la regulación de la posible sustitución de la competencia local por la autonómica en estos términos, desdice bastante el propósito expuesto por la norma autonómica.

Por lo que se refiere a la mecánica procedimental de ambas regulaciones, nada hay que objetar, en principio, a la del art. 35,1 , en la medida que prevé el previo requerimiento, con fijación de plazo, para la elaboración, plazo cuyo desatendimiento municipal equivaldría a la abdicación de su competencia y legitimaría la actuación autonómica.

No es tan nítida la redacción cuando la norma - art. 36-se refiere a la revisión o modificación del planeamiento. En estos casos hay que entender -aunque no se haya expresado así - que el requerimiento habrá de ir acompañado de la fijación del plazo de atendimiento voluntario del mismo por la Corporación Local ${ }^{23}$.

Por estas mismas razones, no puede extenderse la expresada opinión a la elaboración autonómica de planes generales municipales "de urgencia», por más que al informe vinculante del Consejo Superior de Urbanismo se añada el acuerdo del Gobierno Valenciano, que sería - llegado el caso- el que autorizase al Conseller competente para actuar, elaborando el Plan, así como que -dada la complejidad que la elaboración de un plan comporta- no sea fácil que esta situación se dé con frecuencia.

\section{TRAMITACIÓN}

Elaborado el proyecto de plan, el municipio ya está en condiciones de someterlo a información pública, informe de las demás Administraciones competentes y dictamen de los municipios colindantes (art. 38,2, LRAU).

También está en condiciones de resolver acerca de la suspensión del otorgamiento de licencias, aspecto este en que la LRAU nada ha innovado, remitiéndose literalmente a la normativa estatal (art. 57).

\section{Ausencia de aprobación inicial}

Constituye novedad, en cambio, que, conforme a la LRAU, no haya que aprobar inicialmente el proyecto de Plan.

22 J. Gonż̇lez PĖrez, Comentarios a la Ley del Suelo, Civitas, Madrid, 1993, 6. Ed., pág. 819.

23 Veáse nota 21. 
La primera impresión es que se trata de una laguna incomprensible.

Como, con mejor técnica que la LRAU, establece el art. 128,1 del R. Planeamiento, la aprobación inicial y el sometimiento a información pública del proyecto, son dos acuerdos distintos. Esta misma conclusión se deduce del art. 114,1 de la LS, quizá porque éste ha sido siempre el procedimiento de aprobación de las disposiciones locales, el art. 49 de la LRBRL lo refleja hoy día y puede acudirse a EMBID IRUJO ${ }^{24}$ quien analiza por separado ambas actuaciones, atribuyendo a cada una de ellas el significado y trascendencia que tienen.

En los Aprontes editados por la propia Administración autonómica, sin embargo, se configura como una determinación deliberada: «No hay, propiamente hablando, acuerdo de aprobación inicial. Lo que debe haber es un acuerdo o resolución por el que se somete a información pública el expediente ${ }^{25} \%$.

Sin embargo, la propia norma parece desmentir esta impresión, cuando, tras la información pública, exige la previa «aprobación provisional», para la remisión de lo actuado a la Comunidad Autónoma. Si estuviésemos ante una omisión deliberada, no tendría sentido calificar esta aprobación como provisional, pues no hay que diferenciarla de ninguna otra que se produzca en sede municipal; hubiese resultado mucho más simple y comprensible obviar toda referencia a aprobación en la fase municipal de este procedimiento ${ }^{26}$, en el que hasta ahora la aprobación provisional venía a confirmar o modificar lo resuelto con carácter inicial.

No obstante, éste es quizá el menor de los problemas que se vislumbran. Resulta francamente dificil entender que una Administración someta a la consideración de sus ciudadanos y de otras Administraciones un proyecto sobre el que previamente no se ha pronunciado, que no puede vincularle; hace que el trámite carezca de todo vestigio de seriedad jurídica. Al ciudadano y a las restantes Administraciones se les solicita opinión, informe o dictamen sobre un proyecto acerca del cual la solicitante no se pronuncia, salvo que se entienda que el hecho de someterlo implica la aceptación del mismo por parte del Municipio por el que ha sido redactado, idea que si bien puede ser admisible, resulta innegable que jurídicamente es muy compleja, máxime cuando la LRAU dota de un va-

24 A. EMBDD IRUso, Ordenanzas y reglamentos municipales en el Derecho español, IEAL, Madrid, 1978 , pág. 486 y ss.

25 Apuntes..., cit.

26 En realidad, hubiese sido suficiente con eliminar la adjetivación de la única aprobación municipal que existe en la LRAU, solución - por otra parte - técnicamente más correcta, como tuve ocasión de defender en La responsabilidad patrimonial..., cit., pág. 19. 
APROBACIÓN DE PLANES GENERALES DE ORDENACIÓN URBANA...

lor superior a este documento al considerar que ninguna alteración que experimente con ocasión de su exposición pública requerirá la repetición de ésta ${ }^{2}$.

\section{Información pública}

La información pública resulta, en cualquier procedimiento, un elemento importante de contraste entre los intereses particulares y los públicos. Adquiere todo su significado cuando permite al ciudadano trasladar sus opiniones acerca de la oportunidad de un proyecto. Si se tiene en cuenta, además, el elevado grado de discrecionalidad que disfruta la Administración en la configuración del modelo urbanístico que elija, tendremos reunidos los suficientes elementos de juicio -oportunidad y discrecionalidad - como para considerar especialmente inadecuado que las posibles discrepancias hayan de resolverse en la vía judicial.

Por lo que se refiere a los aspectos formales del trámite, éste tendrá una duración mínima de un mes, período en el que el proyecto se someterá también a los informes que la legislación sectorial determine, en razón del ejercicio de competencias de otras Administraciones distintas a la Autonómica, excepción hecha de los Planes Generales, que habrán de ser sometidos al preceptivo informe de los Departamentos competentes en Educación y Sanidad. En este mismo plazo el proyecto se someterá al dictamen de los municipios colindantes o de todos los afectados, si el proyecto es promovido por una Administración no municipal.

Practicada la información pública, la Administración está obligada a notificar el acuerdo que se adopte sobre su reclamación. Esto es lo que hay que deducir del párrafo segundo del art. 38,2,A) LRAU, que no es un modelo de claridad.

Si bien los Apuntes (2828. Cfr. pág. 25), recogen la obligación de notificar el acuerdo a quienes hayan formulado alegaciones, el recién citado precepto lo que dispone es que si, con ocasión de la aprobación provisional, se introducen modificaciones sustanciales en el proyecto, será necesario notificarlo a los interesados personados en las actuaciones, lo que parece reducir esta obligación al supuesto en que se dé esa notable variación entre el proyecto sometido a información pública y el aprobado provisionalmente.

Ciertamente, nuestros Tribunales no han mantenido una línea homogénea. La Sala de Valencia valora el defecto de notificación en función de que haya

27 Reduce todavía más el grado de vinculación de la Administración con el proyecto; no sería mayor que la que se da respecto del Avance, al que ya se ha hecho referencia. 
causado una indefensión efectiva ${ }^{28}$. El Tribunal Supremo reconoce que, aunque la participación en el trámite no confiere la condición de interesado ${ }^{29}$, existe la obligación de notificar a los comparecidos, no siendo suficiente la publicación ${ }^{30}$.

Actualmente, la interpretación de este mandamiento legal debe vincularse al art. $86 \mathrm{LPC}^{31}$, del que, en síntesis, se desprende la obligación de notificar a los comparecidos, obligación que no supone reconocer a éstos la condición de interesados. No detalla la norma procedimental el momento en que haya de practicarse la notificación, por lo que hay que suponer que tal momento será el de la aprobación definitiva.

Respecto a los informes y dictámenes, si no se emiten en el plazo de un mes, no paralizan el procedimiento. En este aspecto, la LRAU sigue al art. 83,4, primer párf. de la LPC. No obstante, debe entenderse igualmente aplicable el párf. $20^{\circ}$ del citado artículo, que permite no tener en cuenta el contenido de los informes emitidos fuera de plazo.

Concluido el plazo y evacuadas las alegaciones, informes y dictámenes, se hace preciso resolver sobre los mismos.

\section{Aprobación provisional}

Esta resolución será, en principio, la aprobación provisional, art. 38,3 LRAU, en la que pueden introducirse las rectificaciones que sean pertinentes -oportunas dice el texto legal- siendo a partir de entonces remitido a la $\mathrm{Co}$ munidad Autónoma para su definitiva aprobación.

Este nuevo trámite merece dos tipos de consideraciones, sobre su contenido, la primera; relacionada con las llamadas modificaciones sustanciales, la segunda.

\section{A. Contenido}

Por lo que se refiere a la primera consideración de las que parecen atinentes, en este punto la Ley introduce un - digamos — cierto sobresalto procedimental. Las reclamaciones presentadas por los ciudadanos, las cuestiones que susciten los in-

\footnotetext{
28 Vid. STSJCVSCA n. ${ }^{\circ} 253 / 1990$.

29 Cfr. STS de 10 de octubre de 1989, R 7351.

30 Cfr. SSTS de 27 de marzo de 1991, R 2022, que resume la doctrina.

31 A pesar de que generalmente se distingue este trámite por su objeto, que no es proteger intereses particulares, sino que la Administración obtenga mayor información. Cfr. STS de 10 de octubre de 1989, R 7351.
} 
APROBACIÓN DE PLANES GENERALES DE ORDENACIÓN URBANA...

formes de las distintas Administraciones competentes afectadas por el proyecto y los dictámenes de los municipios colindantes, habrán de ser resueltas por el Ayuntamiento, con ocasión de la aprobación provisional.

Resulta muy inadecuada la denominación del trámite, puesto que implica revisar un proyecto sobre el cual el Ayuntamiento todavía no se ha pronunciado ${ }^{32}$.

La aprobación llamada provisional es considerada como «la cristalización de la voluntad municipal» ${ }^{33}$, también, como un trámite ${ }^{34}$ equivalente a la propuesta de resolución del procedimiento general que, aun sin estar vinculado por lo inicialmente aprobado, supone confirmar o alterar lo inicialmente resuelto ${ }^{35}$. En los procedimientos que concluyen con la aprobación definitiva autonómica, este trámite tiene la importancia de fijar por última vez la posición municipal, incluso para quienes todavía mantienen la calidad meramente tutelar de la aprobación definitiva ${ }^{36}$, la provisional es la decisión realmente sustantiva.

\section{a. Aprobación provisional y participación ciudadana}

Con ocasión de la adopción de este acuerdo, el Ayuntamiento habrá de pronunciarse sobre las alegaciones que hayan sido presentadas en la información pública, aunque, dada la naturaleza de trámite no cualificado de la aprobación provisional, que no pone fin al procedimiento, ni conlleva, en sí misma, consecuencias jurídicas, no se procederá a su notificación.

\section{b. Aprobación provisional y conflictos interadministrativos}

\section{a'. Planteamiento del conflicto}

Con ocasión de la aprobación provisional del proyecto, el Ayuntamiento debe pronunciarse también acerca de los informes y dictámenes que se hayan presentado. Si aquéllos discrepan del proyecto, la Ley arbitra un procedimiento específico de solución de las diferencias.

\footnotetext{
32 Recuérdese que en la LRAU no hay acto de aprobación inicial del proyecto de plan.

33 Cfr. STS de 6 de junio de 1988.

34 Y, en cuanto tal, inimpugnable. SSTS de 14 de febrero de 1986, R 1585 y 15 de diciembre de 1987 , R 9498.

35 Cfr. STS de 14 de abril de 1993, R 2605.

36 Así lo indica A. CARCELler Fernández, Instituciones de Derecho Urbanistico, Montecorvo, Madrid, 5. ${ }^{\circ}$ Ed., 1992, pág. 255.
} 
Éstas aparecen cuando los municipios colindantes manifiesten su desacuerdo con las determinaciones que sobre la adecuación se propongan en el proyecto, tanto con los PAT que le afecten y con el planeamiento de los propios colindantes cuya ordenación debe establecer o reflejar el proyecto, art. 17,6, LRAU— o con las que contenga el proyecto sobre coordinación con el planeamiento general de los municipios en que se dé la situación de conurbación o recíproca influencia prevista en el art. 35,2, LRAU.

También se producen cuando los informes de las Administraciones competentes en virtud de la legislación sectorial o de las Consellerías de Educación y Sanidad - cuyos informes son preceptivos ex art. 38,2,B, de la LRAU-, resulten discrepantes con el proyecto de plan.

Es en estos casos cuando dispone la Ley la intervención de la Comunidad Autónoma. Por consiguiente, no es suficiente que el Municipio apruebe provisionalmente el proyecto para que prosiga el procedimiento.

Para eliminar las discrepancias la LRAU acude al mecanismo de resolución de conflictos previsto en el art. 50,2 de la LRBRL.

Esta actuación ha de ser considerada tanto desde el punto de vista formal, como desde el de su contenido.

\section{b'. Resolución del conflicto}

El conflicto será resuelto por la Consellería competente en materia urbanística. Esta decisión puede recaer antes o después de la aprobación provisional -así lo indica tanto la literalidad del precepto, como el propio art. 38,3, que sigue a éste-. Tal indeterminación legislativa genera confusión.

Como la decisión autonómica puede ser dictada de oficio o a instancia del Ayuntamiento que promueve el proyecto de plan, la más acertada interpretación del artículo será considerar que es la resolución autonómica la que puede recaer antes o después de la aprobación provisional, sin depender del momento en que se produzca esta decisión municipal.

Ahora bien, si aquella decisión se produce después de ésta, el Ayuntamiento deberá volver sobre ella, generando una dilación sin sentido. Pero si recayese antes, lo sería sin que cupiese entender formalizada la discrepancia, pues no se habría expresado la voluntad municipal, máxime teniendo en cuenta que la Ley no prevé la aprobación inicial. Se trata, pues, de otra cuestión a resolver reglamentariamente. 
APROBACIÓN DE PLANES GENERALES DE ORDENACIÓN URBANA...

La consecuencia de todo ello no puede ser otra que la de aceptar que la solución del conflicto debiera producirse una vez el procedimiento entre en la fase autonómica, conclusión ésta a la que también se llega al tomar en consideración que la fórmula mediante la que se solucione el conflicto habrá de ser examinada por las partes, por separado y conjuntamente:

«..., $\mathrm{y}$, antes de resolver, las entidades afectadas podrán emitir informe previo y celebrar, al menos, una reunión conjunta de sus representantes.» (Art. $38,2, \mathrm{C}, \mathrm{LRAU})$.

Desde el punto de vista formal, el informe debiera ser necesario e incorporarse al expediente, es más, temporalmente debería ser posterior a la reunión «conjuntay, salvo que se llegase en ella a algún acuerdo, del que se levantase un acta que pudiese surtir los efectos del informe.

\section{c'. Contenido de la resolución del conflicto}

Más complejo parece otro de los problemas que suscita este procedimiento de conflicto. Se trata de los términos en que puede pronunciarse el órgano autonómico. La LRAU —art. 38,2,C— dice que:

«Esta resolución ha de fijar las bases de coordinación interadministrativa, compatibilizando el ejercicio sobre el territorio de las competencias de cada ente público. Se adoptarán aquellas soluciones más adaptadas a las directrices de los Planes de Acción Territorial, si los hubiera....».

Salvo que existan los PAT y contengan unas directrices lo suficientemente claras como para rechazar alguna de las posiciones en conflicto - con lo cual incluso el proyecto $\tan$ siquiera debería incluirla ${ }^{37}$ - la eficacia de lo dispuesto en el precepto transcrito suscita muchas dudas.

Si dejamos de lado al municipio promotor del proyecto y a los colindantes, no parece que la Comunidad Autónoma pueda imponer a las restantes Administraciones - todas ellas competentes, según el propio precepto legal - la forma en que deben ejercer sus competencias ${ }^{38}$.

37 Cfr. art. 40,1,B, LRAU.

38 En muchos casos ya existen procedimientos específicos, como, por ejemplo, en la ordenación del litoral (arts. 112, 117 de la Ley de Costas 22/1988 y art. 18 de la Ley de Puertos 27/1992). Vid. A. CAR. CELlER FERNÁNDEZ, op. cit., pág. 252, y la STS 30 de enero de 1996. 


\section{B. APROBACIÓN PROVISIONAL Y MODIFICACIONES SUSTANCIALES}

También resulta innovadora la regulación que la LRAU dispensa a la introducción de modificaciones sustanciales, tras la información pública.

Como es sabido, la expresión modificaciones sustanciales se acuña a partir de los arts. 130 y 132 del R. Planeamiento.

El primero garantiza que, si con ocasión de la aprobación provisional se introducen modificaciones que «significasen un cambio sustancial en los criterios y soluciones del plan inicialmente aprobado...», se abrirá un nuevo trámite de información pública; actualmente, el art. 114,2, de la Ley del Suelo -otra incorporación de un reglamento a esta norma legal-, se pronuncia en parecidos términos ${ }^{39}$, que obligan a la Administración a repetir el trámite antes de proceder a la aprobación provisional ${ }^{40}$.

La doctrina de las modificaciones sustanciales ha sido construida fundamentalmente por nuestros Tribunales ${ }^{41}$. Supone una constante en esa doctrina el reconocimiento previo de su apreciación en la determinación de apreciar la necesidad de repetir el trámite de información pública - ante el carácter esencial del trámite y la indefensión ciudadana que su omisión produce o la necesidad de legitimar democráticamente el planeamiento-.

Ahora bien, una vez establecida esa premisa, partiendo de su consideración como concepto jurídico indeterminado, resulta necesario el examen de las circunstancias del caso concreto para llegar a la conclusión de si es aplicable a las mismas dicho concepto.

A estos efectos, los criterios que se siguen, a partir de la Sentencia de 22 de diciembre de 1986, distinguen entre el carácter reglado o discrecional de la modificación y el ámbito territorial afectado por la misma.

Desde el primero de ellos, se excluyen del concepto las alteraciones en la clasificación del suelo urbano, no de las restantes clases, así como las que vengan im-

39 En la Ley es el Plan el que ha de cambiar, no solamente sus criterios y soluciones.

40 Naturalmente, con la LS esta situación puede darse igualmente con ocasión de la aprobación definitiva, art. 132,2,b del R. Planeamiento, incluso con ocasión de la resolución de recursos administrativos interpuestos contra la aprobación definitiva. Vid. STS de 29 de noviembre de 1989, R 8373.

41 Cfr. SSTS de 30 de abril de 1990; 10 de julio de 1991 y 23 de marzo de 1993: R 3627, 6291 y 2524. 
APROBACIÓN DE PLANES GENERALES DE ORDENACIÓN URBANA...

puestas por el ordenamiento jurídico o sean consecuencia del ejercicio de competencias.

Desde el segundo, se admiten las alteraciones que supongan la adopción de un nuevo modelo territorial o esquema de planeamiento, respecto al sometido a información pública, pero se excluye que un elevado número de modificaciones concretas o puntuales tengan la consideración de sustanciales.

El sentido de esta doctrina resulta aceptable en la medida que lo sea la acotación severa del concepto. No obstante, desde su razón de ser -la participación pública- únicamente se comparte el segundo criterio, el material, dado que en el primero se observa una ausencia de relación lógica. Parece indiferente que la modificación le venga impuesta al planificador, pues si es sustancial, le será de aplicación la repetición de un trámite que viene impuesto como consecuencia del derecho a la participación de los ciudadanos.

La LS ha recogido la doctrina jurisprudencial mayoritaria conforme antes ha sido expuesta. En definitiva, ha restringido las posibilidades de un nuevo sometimiento del proyecto al trámite de información pública.

La LRAU, que parte de esas mismas premisas - con una técnica más depurada, que le permite referirse al proyecto y no al plan, como objeto de las modificaciones que puedan ser consideradas sustanciales-, ha adoptado una solución más drástica:

«No será preceptivo reiterar este trámite en un mismo procedimiento, ni aun cuando se introduzcan modificaciones sustanciales en el proyecto, ...» (Art. 38,2,2. ${ }^{\circ}$ párf.).

Al legislador valenciano le parece suficiente garantía que se notifique la aprobación provisional a los interesados personados en las actuaciones ${ }^{42}$.

Sin duda alguna, la crítica a esta decisión del legislador valenciano es sencilla; resulta suficiente recordar el valor jurídico que la jurisprudencia y parte cualificada de la doctrina ${ }^{43}$ otorgan al trámite en cuestión, para razonar la postura contraria a esta determinación normativa.

42 Ello resulta un tanto gratuito, habida cuenta que tal notificación habría de practicarse en todo caso. Cfr. Apdo. Información pública.

43 Vid T. R. Fernández Rodriguez, Manual de Derecho Urbanístico, Abella, Madrid, 1993, pág. 85 y A. Carceller Fernández, op. cit., pág. 254. 
Tal vez, el motivo que haya guiado al legislador sea el de aliviar la tramitación de los proyectos. Tal explicación, en su caso, sería escasamente coherente con la prolijidad del texto legal que se viene analizando. Es excesivamente llamativo el contraste entre la eliminación de la posibilidad de un nuevo trámite de información pública y las reiteradas ocasiones que se atribuyen a las Administraciones Públicas no directamente implicadas en el procedimiento, teniendo en cuenta que éstas disponen de cauces específicos para hacer valer sus planteamientos discrepantes con el de la Administración promotora del proyecto de plan ${ }^{44}$.

Desde una perspectiva puramente urbanística la eliminación de la posibilidad de repetir la información pública, una vez restringido legislativamente el objeto de las modificaciones sustanciales, no constituye un acierto, es, más bien, un retroceso en la apertura del procedimiento al ciudadano. Parece igualmente que podría plantear incluso problemas de constitucionalidad, ante la dimensión que la jurisprudencia y la doctrina han dado a esta forma de participación en los asuntos públicos.

La solución legal, consistente en dejar en manos de los municipios la decisión de repetir el trámite - pues el precepto elimina su carácter preceptivodesplazando hacia éstos la carga de reducir las posibilidades de participación de la ciudadanía en la elaboración del planeamiento, resulta, desde esa perspectiva, relativamente irrelevante, dado que la Constitución remite a la ley la configuración de este derecho.

Descartada la utilidad procedimental y urbanística de la medida, considerado el problema que puede suscitar desde la óptica constitucional, sólo queda pensar que el legislador valenciano se haya movido a impulsos coyunturales ${ }^{45}$, impulsos que normalmente dan a luz soluciones desafortunadas.

\section{APROBACIÓN DEFINITIVA}

\section{Regulación legal}

El legislador valenciano ha creído conveniente determinar el contenido de las actuaciones que haya de seguir la Consellería competente de una manera más sustantiva y menos formal de lo que lo hacen los arts. 114, 2 LS y 131 RP.

\footnotetext{
44 Tanto a través de los informes a que se refiere el art. 39.1.A, como por la participación en los órganos, Ponencia Técnica o la propia Comisión territorial de Urbanismo, etc. Cfr. SSTS de 31 de marzo y 25 de mayo de 1993, R 1608 y 3509, así como la STSJC Valenciana 1/801/1992, sección 1."

45 Se hace referencia a la situación creada por la anulación judicial -STSJCV de 17 de diciembre de 1993, AA 94/205- de la aprobación de un Plan General, elaborado y tramitado por subrogación. El fallo judicial no resulta excesivamente afortunado desde la teoria de las modificaciones sustanciales.
} 
Aprobado provisionalmente el proyecto $-\mathrm{y}$ resueltos previa o posteriormente, en su caso, los desacuerdos entre el promotor del proyecto y las otras Administraciones afectadas - se remitirán las actuaciones a la Consellería competente para su aprobación definitiva (art. 38,3 LRAU).

\section{Período consultivo, en particular, los informes oportunos y el ofrecimiento de alternativas téenicas}

Donde el legislador estatal se refiere a la necesidad de solicitar informes de la Diputación Provincial y la Comisión Provincial de Urbanismo - para municipios de más de 50.000 habitantes - la LRAU (art. 39) dispone la iniciación de un «período consultivo y de análisis» del proyecto, abierto a la Administración promotora y a otras afectadas.

El trámite en cuestión es facultativo, pues podrá ser obviado, en cuyo caso se otorgará directamente la aprobación definitiva; su contenido es asimismo, flexible, pues también prevé la Ley que se realice abreviadamente.

Pendiente como está la LRAU de desarrollo reglamentario, es de suponer que, dadas las consecuencias que la apertura o no del período consultivo puede tener sobre la aprobación presunta - véase el art. 39,2 LRAU—, se exija sea notificada al Ayuntamiento promotor la decisión de realizar o no este trámite.

La Ley también ha fijado el contenido de este período consultivo, en el cual se podrán recabar los informes «oportunos», requerir al promotor para que aclare o subsane las deficiencias u oscuridades del proyecto y ofrecer «alternativas técnicas de consenso interadministrativo».

Naturalmente, nada puede objetarse a la adopción de cualquiera de las determinaciones apuntadas por parte de la Consellería competente. Cuestión distinta es el contenido que se quiera dar al trámite en cuestión.

A) Por informes «oportunos» habrá que entender solamente aquellos que el promotor no haya solicitado durante la tramitación municipal del proyecto, debiendo hacerlo. Recuérdese que en esa fase del procedimiento resulta necesario realizar una serie de negociaciones, consultas, conciertos y recabar distintos informes y dictámenes (art. $38 \mathrm{LRAU}$ ). Se trata de una "oportunidad» entendida como tal por el legislador.

En otro caso, de acuerdo con la mejor técnica legalmente establecida (art. 82, LPC), habrá que justificar la solicitud de nuevo informe a quien ya se le ha pe- 
dido, recordando los efectos de su falta de emisión (arts. 38,2, LRAU y 83,4, LPC).

B) Por lo que se refiere a deficiencias documentales o de trámites no practicados, la regulación que de ambos aspectos existe impide cualquier duda interpretativa. No puede decirse lo propio de la petición de aclaración de las propuestas que contenga el proyecto. En cualquier caso, el $\multimap$ los - requerimientos habrán de ser motivados.

C) El ofrecimiento de alternativas técnicas puede ser objeto de distintas consideraciones.

La posibilidad de que tales alternativas se formulen parece amparada literalmente en la expresión utilizada por el legislador («ofrecerá»), que, complementada con el calificativo asignado a las alternativas ("técnicas»), da a entender que la Consellería competente puede sugerir las que crea conveniente. También aquí la Ley parece necesitada del auxilio reglamentario.

De entrada, es necesario que estas alternativas se funden en las exigencias propias de la política urbanística y territorial de la Comunidad Autónoma.

Estamos ante un requisito exigido por el art. 40,2 de la propia LRAU, que lo considera un límite a la decisión definitiva que ha de adoptarse sobre el proyecto. El ofrecimiento de alternativas injustificadas no vincularían al municipio, de modo que éste podría desecharlas, sin más.

Por otra parte, las alternativas requieren la conformidad del municipio.

Ésta es una deducción a que se puede llegar interpretando que cuando el legislador habla de consenso interadministrativo está poniendo en pie de igualdad al promotor del proyecto y a quien es competente para aprobarlo definitivamente.

Concluyendo con esta cuestión, la apelación legal al consenso administrativo ha de relacionarse con el art. $88 \mathrm{LPC}$, lo que supone que cada Administración actúe dentro de sus competencias.

Ello no obstante, la posición preponderante de la Comunidad Autónoma -que ha de ser quien apruebe el proyecto definitivamente- puede permitirle llegar más allá de sus competencias, es decir, conseguir que el municipio acepte como alternativa "consensuada» aquellas propuestas autonómicas sin cuya incorporación el proyecto no será aprobado, propuestas que, sin embargo, no podrían serle impuestas, pues rebasarían el ámbito decisorio autonómico, limitado a los aspectos supralocales, cuando se trata de aspectos discrecionales del planeamiento urbanístico. 
APROBACIÓN DE PLANES GENERALES DE ORDENACIÓN URBANA.

En fin, este trámite está muy necesitado de desarrollo reglamentario, desarrollo que, además de las cuestiones ya citadas, habrá de abordar igualmente los supuestos en que el propio trámite tenga razón de ser, puesto que, llegados a este punto, los posibles interesados en el procedimiento, sin excepción, ya habrán tenido ocasión de intervenir, por lo cual, una inadecuada aplicación de la regulación actual puede dar paso a convertir un trámite de indudable utilidad en una «nevera» donde almacenar los proyectos que resulten inoportunos por tiempo indefinido, ya que la cantidad de informes, requerimientos y ofertas que pueden formularse resulta indefinida y, dada la regulación de la aprobación por silencio que contiene la Ley, podria no alcanzarse nunca ese objetivo.

Concluida esta fase, puede resolverse definitivamente sobre el proyecto.

El legislador valenciano ha configurado la finalización del procedimiento de aprobación de los planes urbanísticos municipales de acuerdo con el patrón clásico estatal, es decir, previendo que pueda producirse una resolución expresa - con diferentes modalidades - o presunta, por silencio administrativo ${ }^{46}$.

La Ley admite, para la resolución expresa, las mismas modalidades ya conocidas de la legislación estatal, es decir, cabe la posibilidad de aprobar el plan, de suspender esta decisión, de adoptarla con condiciones, o de resolverla parcialmente.

La regulación de la resolución expresa no es un modelo de sistematización. Si se hubiera seguido el orden establecido por el art. $132 \mathrm{RP}$, seguramente el texto legal valenciano habría ganado muchos enteros.

La aprobación definitiva expresa aparece en los arts. 39,1; 40 y 41 ; la presunta, en el art. 39,2, y la parcial y condicionada, en el art. 41 , todos ellos, naturalmente, de la LRAU.

A pesar de lo recién dicho, en ningún momento se dice que la Administración pueda aprobar upura y simplemente» (art. 132,3,a. R. Planeamiento) el proyecto que le es sometido para ello por el municipio.

Tampoco se dice que la aprobación pueda ser denegada. A primera vista, esta objeción puede parecer irrelevante, en particular cuando la naturaleza jurídica de este acto ya no ofrece hoy tantas dudas como en el pasado ${ }^{47}$. Sin em-

\footnotetext{
46 Al decir silencio administrativo se quiere subrayar que el acto presunto se produce sin necesidad de obtener previamente la certificación del mismo.

47 Vid. A. Carceller Fernández, op. cit., pág. 257 e I. Sevilla Merino, Responsabilidad patrimonial..., cit., pág. 36 y ss., donde desde distintas perspectivas y con diferente sistematización se reflejan las posiciones doctrinales sobre el particular.
} 
bargo, en un contexto legal como el que nos ocupa, caracterizado por las limitaciones a la denegación de la aprobación ${ }^{48}$, en lo que parece, más bien, un desarrollo de las posibilidades de los arts. 64 y 66 de la LPC, la alternativa debiera estar expresamente reflejada en la Ley, aunque sólo fuese para despejar posibles malentendidos.

No obstante, con el art. 40 de la LRAU sucede algo parecido a lo que ocurre con el art. 64 de la LPC, es decir, que su título indica exactamente lo contrario al contenido. El art. 40 se titula «Aprobación definitiva» cuando, en realidad, el precepto expresa las causas de denegación de la aprobación, imponiendo la obligación - que aparece recogida en el art. 40,2, in fine- de que la denegación sea motivada.

El apartado primero del artículo determina cuáles pueden ser los fundamentos concretos de la denegación - cita hasta seis-, excluyendo las infracciones legales, que también cita, y los márgenes de actuación competencial autonómica, a los que se refiere el apartado segundo del precepto. Si las objeciones son consideradas por el órgano autonómico como insubsanables, la consecuencia inmediata será la desaprobación del proyecto.

Por último, tampoco parece, en principio, que quepa resolver la suspensión de la aprobación definitiva. Sin embargo, el art. 40,2 se refiere a ella casi incidentalmente: «..., la resolución suspensiva... deberá ser expresamente motivada y concretar el apartado del número anterior en que se fundamente o el precepto legal que entienda infringido».

\section{Tipología}

La aprobación definitiva tiene las siguientes modalidades procedimentales o sustanciales:

\section{A. Aprobación definitiva expresa}

Puede producirse directamente, es decir, sin iniciar el período consultivo y de análisis del art. 39,1 LRAU. Cabe interpretar que cuando se produzca esta modalidad de resolución, la misma se dictará sin ningún condicionamiento, esto es, pura y simplemente, como antes se ha indicado recoge el art. 132,2, a), del RP. Si el proyecto suscita cualquier duda al órgano competente, éste habrá de apurar previa-

48 Cfr. arts. 40 y 41 , LRAU. 
mente las posibilidades que le da la LRAU, iniciándose entonces el período consultivo y de análisis.

A la aprobación expresa puede llegarse igualmente tras haber consumido el trámite consultivo establecido por la Ley como facultativo y comprensivo de todas o alguna de las actuaciones reflejadas en el art. 39,1, pues el período consultivo puede ser abreviado, según dispone dicho precepto. Lógicamente, si el resultado del trámite es satisfactorio - recuérdese ahora lo que antes se ha indicado sobre las alternativas consensuadas- esta resolución también habrá de producirse pura y simplemente.

\section{B. Suspensión de la aprobación}

De acuerdo con la Ley, ésta es una decisión a la que únicamente puede llegarse después de que se hayan agotado las posibilidades de consenso durante el período consultivo. En consecuencia, sólo una vez practicado $-\mathrm{y}$ frustrado- el trámite puede acordarse la suspensión.

Respetuosa como es la Ley con su propia concepción de la autonomía local, dispone que la suspensión se adopte motivadamente, tasando las causas que justifican la suspensión y que son las mismas que pueden fundamentar la denegación de la aprobación (art. 40,1 LRAU), por lo cual, la Ley determina la competencia autonómica para valorar si las objeciones regladas dan pie a la suspensión o a la desaprobación.

Las causas motivadoras del acuerdo de suspensión resultan heterogéneas. En general, todas expresan la preocupación del legislador de facultar a la Comunidad Autónoma para impedir que el proyecto municipal condicione la competencia urbanística autonómica, configurada en la Ley como estrictamente supramunicipal.

Ahora bien, con este nexo de unión, existe un primer grupo de causas, que se configuran como expresivas de la fiscalización -o tutela de legalidad- que se sigue reservando a quien aprueba definitivamente el proyecto y lo convierte en plan.

En este grupo se pueden incluir la clasificación del suelo no urbanizable, conforme a la legislación específica ${ }^{49}$; garantizar que la urbanización se lleve a cabo conforme a las determinaciones de la propia Ley —n realidad,

\footnotetext{
49 Ley de la Generalidad Valenciana 4/92, del Suelo no urbanizable, vid. D. Adicional séptima de la LRAU.
} 
se tratará de comprobar que el proyecto contiene las previsiones oportunas al respecto- y comprobar que el proyecto no infringe leyes estatales o autonómi$\operatorname{cas}^{50}$.

Un segundo grupo está formado por aquellas causas que persiguen el aseguramiento de la jerarquía del planeamiento urbanístico o sectorial. Aquí se incluyen los PAT y las políticas de conservación del patrimonio cultural, de vivienda o ambiental ${ }^{51}$.

El último grupo está integrado por causas que se configuran como de protección de las competencias urbanísticas autonómicas, es decir, referidas a los aspectos supramunicipales de los planes de ordenación urbana ${ }^{53}$.

Las anteriores son causas tasadas, en el sentido que cabe deducir del art. 40,2, de la LRAU que exige a la resolución adoptada que concrete cuál es - de entre los citados- el apartado en que se funda y, en su caso, el precepto legal infringido, con lo que esta decisión se convierte también en preceptivamente motivada.

Sobre esta decisión pende igualmente el límite general que también cita el precepto y que enlaza directamente con la Exposición de Motivos de la LRAU y con la doctrina de nuestros tribunales ${ }^{53}$. En consecuencia, la Comunidad Autónoma no podrá cuestionar la interpretación que de los intereses públicos locales hagan los municipios, ateniéndose exclusivamente a sus competencias.

\section{Aprobación parcial}

La aprobación definitiva parcial se produce cuando la decisión se refiere solamente a una parte del ámbito territorial del proyecto de plan ${ }^{54}$.

Esta modalidad de aprobación definitiva (art. 41 LRAU), constituye una fórmula plenamente aceptada doctrinal y jurisprudencialmente ${ }^{55}$, que, incluso,

So Estas causas figuran en el art. 40,1, apdos. A, D y segundo párf. del F.

51 Art. 40,1, apdos. B, segundo párf., y F.

52 Apdos. B y C, del art. 40,1.

53 Cfr. R. Gómez-FerRer MORANT, «La legislación en materia de urbanismo: competencias de la Comunidad y novedades más significativas" en Estudios sobre el Derecho de la Comunidad de Madrid, Civitas, Madrid, 1987; L. MORELl OCAÑA, «La coordinación del Estado y las Comunidades Autónomas con la Administración local) Documentación Administrativa n. ${ }^{\circ}$ 230-231, 1992 e I. SEVILLA MERINO, La responsabilidad patrimonial..., cit.

54 STS de 11 de mayo de 1989; R 3868. 
APROBACIÓN DE PLANES GENERALES DE ORDENACIÓN URBANA...

se entiende ínsita, tanto en el art. 56 de la LS de 1956, como, posteriormente, en el art. 132,3,a, del R. Planeamiento.

En realidad, no puede afirmarse esto con tanta rotundidad, habida cuenta que el precepto reglamentario a lo que se refiere es a la suspensión de la decisión, en este caso, autonómica. Pero considerando que ha sido admitida esta fórmula en aras a los principios de eficacia y de favorecer la autonomía municipal, - lo cual es cierto, si se compara con su alternativa, la suspensión de la aprobación-y, sobre todo, si se tiene en cuenta que la fórmula es expresamente recogida por el legislador valenciano, tampoco cabe hacer mayor cuestión de ella.

Naturalmente, las consecuencias de esta fórmula aprobatoria serán la entrada en vigor del plan —en la parte aprobada-y la ausencia interina de planeamiento, en el suelo afectado por la falta de aprobación.

Formalmente, la decisión habrá de ser adoptada con las garantías ya examinadas, para los casos de suspensión.

En cuanto a los términos en que puede ser adoptada la decisión, al cumplimiento de los límites consignados en el art. 40,2, LRAU, hay que añadir los que hasta ahora han sido establecidos por la jurisprudencia, que pueden concretarse en la admisión de esta fómula, siempre y cuando no quede perjudicada la coherencia del plan parcialmente aprobado ${ }^{56}$. A ello habría que añadir en aras a la seguridad jurídica, la conveniencia de fijar un plazo máximo en que completar la aprobación.

\section{Aprobación condicionada}

La aprobación parcial y la condicionada son modalidades cuya distinción no resulta excesivamente sencilla. Cuando la decisión hace únicamente referencia a condiciones necesarias para la aprobación, se estará ante la suspensión de la aprobación o aprobación condicionada.

Sucede, sin embargo, que la aprobación condicionada no ha llegado a figurar con esa denominación en la legislación estatal que recoge la LRAU en su art. 41 .

S5 SSTS de 2 y 28 de junio de 1993, R 4512 y 5027.

56 STS de 6 de febrero de 1988, R 783. 
De la ausencia de previsión legal o reglamentaria se ha derivado cierta resistencia a la admisión de esta modalidad de aprobación ${ }^{57}$, que, propiamente hablando, es una suspensión, o, en su defecto, habría de ser considerada como la desaprobación del proyecto presentado ${ }^{58}$.

Con todo y con ello, estamos ante una cuestión de matiz, pues resulta indiferente afirmar que un plan está aprobado bajo condición de que se introduzcan en el mismo ciertas modificaciones, o que está pendiente de ser aprobado, tan pronto como esas modificaciones sean introducidas en el proyecto.

En cualquier caso, la fórmula ahora establecida en la LRAU no puede servir para ocultar o disimular infracciones al ordenamiento jurídico ${ }^{59}$. Únicamente se admitirá esta fórmula en relación con deficiencias subsanables.

\section{E. Aprobación por silencio administrativo}

Está prevista en el art. 39,2 de la LRAU de un modo que resulta muy insatisfactorio, desde el punto de vista de su posible aplicación.

La mecánica del sistema establecido exige que transcurridos cuarenta días desde la presentación del proyecto para su aprobación definitiva y atendidos -en su caso- los requerimientos realizados, se solicite «que se resuelva sin más dilación». Si transcurren tres meses desde esta solicitud, sin que la Comunidad Autónoma resuelva, se podrá requerir a la Generalitat el reconocimiento y publicación de la aprobación definitiva.

La explicación de este precepto quizá se encuentre en las vicisitudes sufridas por la Comunidad Autónoma con ocasión de la aprobación definitiva del Plan General de Valencia ${ }^{60}$.

Lo primero que hemos de observar es la complejidad del procedimiento. No es suficiente con la presentación del proyecto para entender solicitada su aprobación, es preciso, además, efectuar una nueva petición transcurridos cuarenta días desde la presentación y que la Administración no resuelva sobre ella en el plazo de tres meses, rebasado este último plazo, todavía será necesario un tercer requeri-

57 Cfr. SSTS de 9 de julio de 1985, R 4937 y 4 de mayo de 1990, R 3800.

58 Vid. la segunda de las sentencias citadas en la nota anterior.

59 STS de 12 de febrero de 1991; R 941.

60 Vid. I. Sevilla Merino, «Doctrina y Jurisprudencia sobre la aprobación de los planes urbanisticos municipales", en Revista General del Derecho, n. ${ }^{\circ} 600$, Valencia 1994, págs. 9.547 y ss. 
APROBACIÓN DE PLANES GENERALES DE ORDENACIÓN URBANA...

miento para que la Comunidad Autónoma «reconozca y publique la aprobación definitiva»s.

En realidad, resulta dificil considerar que pueda hablarse de aprobación por silencio cuando la Ley exige — después de que el Ayuntamiento lo solicite tres veces - un acto expreso autonómico, de reconocimiento de la aprobación definitiva, que deberá ser publicado por ella misma.

Con ello la regulación legal parece quedar a medio camino entre el silencio administrativo de la LPA y la certificación del acto presunto en la LPC. El acto de reconocimiento con que concluye la LRAU se aproxima bastante a la certificación comprensiva de los efectos de la ausencia de resolución expresa, a que se refiere el art. 44,3, de la Ley 30/1992.

Sin embargo, en la Ley valenciana no quedan claras las posibilidades de resolver que retiene la Comunidad Autónoma, una vez se efectúa el requerimiento, lo que es particularmente interesante tras haber repasado las modalidades que puede revestir la aprobación de los planes urbanísticos. ¿Podría «reconocerse» una aprobación parcial o condicionada?

Si pensamos en la LS o, incluso, en la LPC, no se puede llegar más que a la conclusión de que lo único que puede reconocerse, llegados a este punto, es la aprobación pura y simple del proyecto de plan, puesto que del régimen general se deduce que el sentido del acto presunto debe estar predeterminado, en tanto que en la normativa estatal las posibilidades de esta resolución se limitan a la aprobación sin adjetivos.

Por fin, un detalle de relativa menor entidad es el concerniente al cómputo de los plazos, más concretamente, al intermedio, es decir, al que se inicia tras la segunda solicitud. Este plazo no concluye más que si transcurridos tres meses la Administración Autonómica no resuelve, a diferencia de lo establecido en la legislación estatal, con arreglo a la que resulta preceptivo comunicar la resolución. Llegar a esta conclusión, es decir, que el dies ad quem es el de la notificación, es cuestión a la que la jurisprudencia ha dedicado frecuentes razonamientos que no dejan lugar a duda alguna ${ }^{61}$.

Es cierto que nada parece impedir al legislador que determine el modo en que considere más conveniente la forma de computar los plazos. En concreto, la fecha de notificación y no la de resolución era la utilizada sin excepciones por nuestro ordenamiento en la fecha de aprobación del Texto Refundido de la

61 Cfr. STS de 8 de julio de 1985, R 4935 y las citadas en ésta. 
Ley del Suelo, como puede comprobarse en los arts. 94 y 125 de la LPA y el antiguo 54 de la Ley de la Jurisdicción Contencioso-Administrativa.

Sin embargo, la LPC, en distintos preceptos (arts. 43,1;44,4; 111,4; 117 y $119,3)$, se refiere a la fecha de la resolución, como el momento a partir del cual el interesado puede entender producidos los efectos que cada uno de ellos regula.

Algunos comentaristas de la norma procedimental común han interpretado «..que lo relevante será que en dicha fecha la Administración no haya notificado todavía resolución alguna»; «No basta, por tanto, con haber dictado la resolución sin haberla notificado al particular para evitar que se produzca el acto presunto ${ }^{62} \%$.

Parecen más bien reflexiones fruto de la inercia interpretativa de los preceptos procedimentales derogados, dado que la claridad y reiteración de la Ley $30 / 92$ no permiten defender esa opinión, que, sin embargo, parece muy respetable desde el principio de seguridad jurídica, pues la demora que normalmente puede sufrir una resolución hasta llegar a manos de su destinatario puede ocasionar a éste la necesidad de realizar numerosas actuaciones que pueden revelarse estériles.

\section{F. Denegación de la aprobación}

A esta posible decisión le son de aplicación las observaciones formuladas sobre la suspensión de la aprobación. La Ley le dispensa idéntico tratamiento, lo cual resulta lógico, en la medida que en ambos casos se trata de una decisión que limita el ejercicio de las competencias locales sobre el planeamiento urbanístico de su propio territorio, lo que justifica que el respeto manifestado por el legislador cuando expresa los términos en que debe decidirse la denegación de la aprobación definitiva sean igualmente aplicables a la suspensión de dicha decisión, que, por consiguiente, habrá de ser concretamente motivada, además de quedar sometida al límite genérico de no incidir en los intereses públicos locales.

62 Cfr. Estudios y comentarios sobre la Ley de régimen juridico de las Administraciones Públicas y del procedimiento administrativo común, BOE, Madrid, 1993, T. I, pág. 239. También en Administración Pública y procedimiento administrativo, Departamento de Derecho Administrativo y Procesal. Universidad de Barcelona. Bosch, Barcelona, 1994, pág. 183. 